\title{
Effects of verapamil and nisoldipine on human platelets: in vivo and in vitro studies
}

\author{
C. R. JONES, F. PASANISI, H. L. ELLIOTT \& J. L. REID \\ Department of Materia Medica, Stobhill General Hospital, Glasgow G21 3UW, UK
}

1 Inhibition of platelet aggregation was observed after 4 days of oral dosing with the calcium antagonists, verapamil $(160 \mathrm{mg})$ or nisoldipine $(20 \mathrm{mg})$ but not following acute dosing. These effects were observed at plasma concentrations that had no effect on platelet aggregation when investigated in vitro.

2 Verapamil added in vitro inhibited adrenaline-induced platelet aggregation at relatively low concentrations ( $\mathrm{IC}_{50} 16 \mu \mathrm{M}$ ) but only inhibited aggregation to adenosine diphosphate at very high concentrations $\left(\mathrm{IC}_{50} 700 \mu \mathrm{M}\right)$.

3 Nisoldipine, a dihydropyridine, added in vitro had no effect on platelet aggregation induced by adenosine diphosphate but inhibited by $67 \%$, the secondary phase of platelet aggregation induced by adrenaline.

4 Verapamil but not nisoldipine displaced $\left[{ }^{3} \mathrm{H}\right]$-yohimbine from the specific binding sites on human platelets, suggesting an interaction with $\alpha_{2}$-adrenoceptors.

5 Inhibition of adrenaline-induced aggregation by verapamil in vitro may be a result of antagonism of $\alpha_{2}$-adrenoceptors but long term treatment with both verapamil and nisoldipine also inhibits platelet aggregation mechanisms other than by $\alpha_{2}$-adrenoceptor blockade.

Keywords platelets verapamil nisoldipine $\alpha$-adrenoceptor blockade

\section{Introduction}

Calcium ions are involved in several stages of platelet activation including platelet adhesion to endothelium, platelet shape change, the excitation contraction coupling in the release of vasoactive substances and the synthesis of the metabolites of arachidonic acid (Ardlie, 1982). Similarities exist between the role of calcium in platelet activation and in contraction of vascular smooth muscle. In smooth muscle calcium antagonist drugs will reduce both the entry of calcium associated with agonist activation (Vanhoutte, 1982; Rosenberg et al., 1979) and the mobilisation of intracellular calcium from sites of storage (Wang et al., 1984). Enhanced platelet aggregation to a variety of stimuli has been found in both hypertension (Mehta \& Mehta, 1981) and ischaemic heart disease (Burns \& Frishman, 1983). In view of the key role of calcium in platelet aggregation, calcium antagonists may exert antiplatelet activity which

Correspondence: Dr C. R. Jones, University Department of Materia Medica, Stobhill General Hospital, Glasgow, G21 3UW 
may expand the therapeutic role of these agents. The aim of the present study was to examine the antiplatelet actions of two structurally different calcium antagonists, the dihydropyridine derivative nisoldipine and verapamil.

\section{Methods}

\section{General protocol}

This crossover, randomised treatment order study enrolled nine healthy normotensive males, aged 20-32 years, who were non smokers. One subject was excluded from the analysis because of an allergic reaction to verapamil. None was taking any concurrent prescription or non prescription drugs, including salicylates for at least 2 weeks prior to the study and all subjects abstained from alcohol during the study period. The study protocol was approved by the Research and Ethics Committee of the Northern District of the Greater Glasgow Health Board and all subjects gave written informed consent. Each subject was studied on six separate occasions when they had been receiving treatment with inactive placebo tablets (two occasions), after the first dose of verapamil (160 mg) (Abbott UK), after verapamil ( $80 \mathrm{mg}$ twice daily for 4 days), after the first dose of nisoldipine $(20 \mathrm{mg}$ ) (Bayer UK Ltd) and nisoldipine ( $20 \mathrm{mg}$ daily for 4 days). Treatment order was randomly assigned and the volunteer unaware of when active treatment or placebo was being given. There was a 12 day washout period between treatments. Blood samples were withdrawn from an indwelling cannula in a forearm vein $2 \mathrm{~h}$ after calcium antagonist administration. The subjects had been recumbent for at least $2.5 \mathrm{~h}$.

Plasma verapamil and norverapamil, a major metabolite, concentrations were measured by h.p.l.c. with fluorescence detection (Cole et al., 1981).

\section{Platelet preparation and aggregation}

Venous blood samples were anticoagulated with one volume of $3.28 \%$ sodium citrate to nine volumes of blood and centrifuged at $180 \mathrm{~g}$ for 15 min at $20^{\circ} \mathrm{C}$ to prepare platelet rich plasma (PRP). Platelet poor plasma was prepared by further centrifugation of the remaining blood at $1700 \mathrm{~g}$ for $15 \mathrm{~min}$. Platelet aggregation was quantified by the turbidometric method of Born (1962). The change in optical density through the samples was measured in a Payton dual channel aggregometer. Aggregation studies were performed at platelet counts of $300 \times 10^{9} \mathrm{l}^{-1}$ adjusted by platelet poor plasma after counting in a Coulter counter at a wavelength of $880 \mathrm{~nm}$.

In vitro additions were made of adenosine diphosphate (ADP) (Sigma Chemical Company) or (-)-adrenaline bitartrate (Sigma Chemical Company) dissolved in $0.9 \%$ saline with $1 \mathrm{~mm}$ ascorbic acid and diluted from stock solution stored at $-70^{\circ} \mathrm{C}$. A dose response curve to adrenaline was produced by plotting the concentration of adrenaline (11-12 concentrations) against the maximum rate of aggregation and the results fitted by an iterative technique to a generalised model of the Hill equation to obtain parameter estimates for maximum aggregation $\left(R_{\max }\right)$ and the concentration of adrenaline required to produce $50 \%$ maximum aggregation $\left(\mathrm{C}_{50} \mu \mathrm{M}\right)$. For determination of inhibitory responses the response was plotted against the concentration of antagonist required to cause $50 \%$ inhibition, at agonist concentrations of $1 \mu \mathrm{M}$ for adenosine diphosphate and $5 \mu \mathrm{M}$ for adrenaline. Verapamil was dissolved in $0.9 \%$ saline and nisoldipine in $1 \%$ ethanol in platelet poor plasma. All experiments with nisoldipine were performed under sodium light as this dihydropyridine is photolabile in ultraviolet light.

\section{$\alpha_{2}$-adrenoceptor binding assay}

Platelet rich plasma was spun at $1700 \mathrm{~g}$ for $15 \mathrm{~min}$ at $4^{\circ} \mathrm{C}$ to produce a platelet pellet. The pellet was suspended in $0.1 \%$ EDTA $150 \mathrm{mM} \mathrm{NaCl} \mathrm{pH}$ 7.4 to give a platelet concentration of $100 \times 10^{9}$ platelets $^{-1}$. Whole platelet suspensions $(0.8 \mathrm{ml})$ were incubated for $20 \mathrm{~min}$ at $25^{\circ} \mathrm{C}$ with $6.5 \mathrm{nM}$ $\left[{ }^{3} \mathrm{H}\right]$-yohimbine in triplicate with varying concentrations of nisoldipine and verapamil. Non specific binding was defined by $1 \mu \mathrm{M}$ phentolamine; incubations were terminated with $20 \mathrm{ml}$ of ice cold Tris ( $50 \mathrm{mM} \mathrm{pH} \mathrm{7.4)} \mathrm{through} \mathrm{a} \mathrm{Milli-}$ pore multiport filtration apparatus on to Whatman GFC filters and bound radioactivity determined by liquid scintillation counting. The $K$ was calculated from the $\mathrm{IC}_{50}$ values for inhibition of binding of the $\alpha_{2}$-adrenoceptor ligand $\left[{ }^{3} \mathrm{H}\right]$ yohimbine which were found from dose-response curves for verapamil inhibition of $\left[{ }^{3} \mathrm{H}\right]$-yohimbine binding and converted into $K_{\mathrm{i}}$ values according to the equation of Cheng \& Prussof (1973):

$$
K_{\mathrm{i}}=\frac{\mathrm{IC}_{50}}{\mathrm{~S} / K_{\mathrm{D}}+1}
$$

$\mathrm{IC}_{50}$ is the concentration of the competing agent which inhibits specific $\left[{ }^{3} \mathrm{H}\right]$-yohimbine binding by $50 \%$. S is the concentration of $\left[{ }^{3} \mathrm{H}\right]$-yohimbine in the assay $(6.25 \mathrm{nM})$ and $K_{\mathrm{D}}$ is the equilibrium 
dissociation constant for $\left[{ }^{3} \mathrm{H}\right]$-yohimbine binding determined from saturation experiments from the six subjects whose blood was used in the displacement $K_{\mathrm{D}} \mathrm{nM}(2.42 \pm 1.02, n=6)$.

\section{Statistical analysis}

Statistical analysis was by paired Student's $t$-test with $P<0.0125(0.05 \div 4)$ taken as significant to allow for multiple comparisons (Ingelfinger et al., 1983). All results are expressed as mean \pm s.d.

\section{Results}

In vitro studies

Platelet aggregation Verapamil inhibited the aggregatory response to adrenaline. The $\mathrm{IC}_{50}$ was $16.8 \pm 2.6 \mu \mathrm{M}$. The aggregatory response to adenosine diphosphate was also inhibited but the concentrations to inhibit the response by $50 \%$ was over 40 -fold higher at $723 \pm 102 \mu \mathrm{M}$ (Figure 1). Nisoldipine at a concentration of up to $100 \mu \mathrm{M}$ had no effect on the primary aggregatory response to adrenaline concentration range but caused a $67 \% \pm 13 \%$ "inhibition of the secondary aggregation response to $5 \mu \mathrm{M}$ adrenaline (Figure 2) when compared with the control response in the presence of vehicle. There was no alteration of aggregatory response to $1 \mu \mathrm{M}$ adenosine diphosphate.

Radioligand binding Verapamil inhibited the binding of $\left[{ }^{3} \mathrm{H}\right]$-yohimbine to platelets with an $\mathrm{IC}_{50}$ of $2.73 \pm 0.26 \mu \mathrm{M}\left(K_{\mathrm{i}}=0.75 \mu \mathrm{M}\right)$ whereas nisoldipine did not affect $\left[{ }^{3} \mathrm{H}\right]$-yohimbine binding (Figure 3).

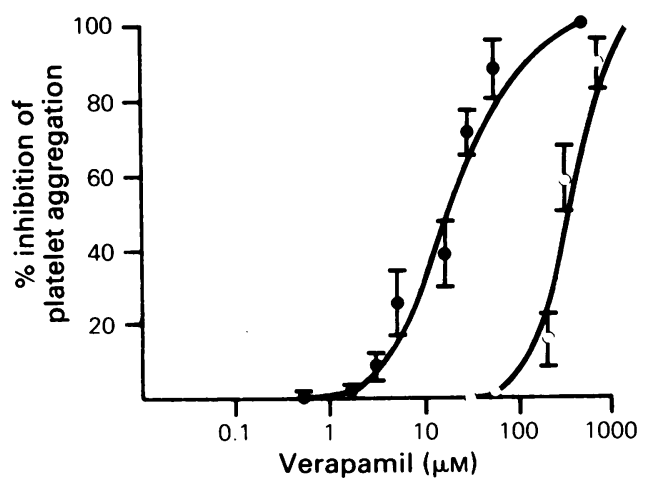

Figure 1 The percentage inhibition by verapamil of the primary aggregation response to adrenaline $(5 \mu \mathrm{M})$ $(\bullet)$ and the threshold response to adenosine diphosphate $(1 \mu M)(0) n=6$.

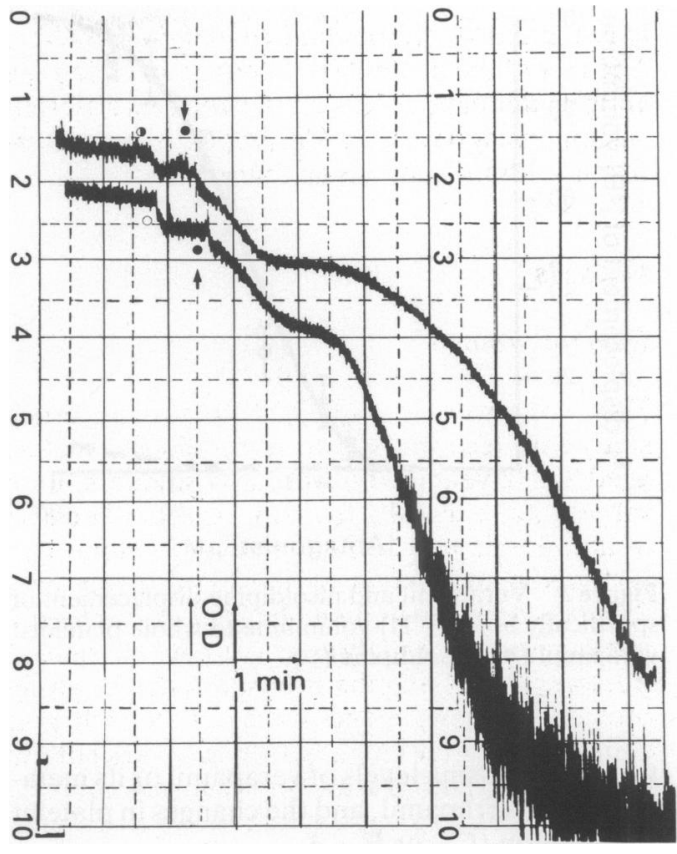

Figure 2 A representative platelet aggregation tracing for the inhibition of secondary platelet aggregation by nisoldipine; the ordinate represents optical density and the time scale of 1 min marked for the abscissa.

Top tracing adrenaline $(5 \mu \mathrm{M}$ arrow) in the presence of nisoldipine $(100 \mu \mathrm{M})(\mathcal{O})$. Bottom tracing adrenaline ( $5 \mu \mathrm{M}$ arrow) in the presence of vehicle $(\mathrm{O})$.

In vivo studies

Platelet aggregation Neither nisoldipine nor verapamil had any significant effect on the aggregatory responses to adenosine diphosphate either after acute dosing or after 4 days treatment (Table 1). Verapamil for 4 days altered the aggregatory dose response curve to adrenaline (Figure 4) with significant reductions in both the maximal rate of aggregation from $47 \pm 18$ to 28 $\pm 16 \Delta \mathrm{OD} / \mathrm{min}(P<0.002)$ and increases in the $\mathrm{C}_{50}$ for adrenaline induced aggregation from $0.77 \pm 0.25$ to $1.14 \pm 0.54 \mu \mathrm{M}(P<0.003)$. Nisoldipine after 4 days caused an increase in the $\mathrm{C}_{50}$ value but no change in the maximal rate of aggregation.

\section{Plasma levels of verapamil and nisoldipine}

The plasma levels of verapamil were $151 \pm 66 \mathrm{ng}$ $\mathrm{ml}^{-1}$ and $166 \pm 95 \mathrm{ng} \mathrm{ml}^{-1}$ at $2 \mathrm{~h}$ after the first dose and 4 days dosing respectively. The plasma levels on the metabolite, norverapamil, at these times were $93 \pm 52 \mathrm{ng} \mathrm{ml}^{-1}$ and $160 \pm 83 \mathrm{ng} \mathrm{ml}^{-1}$ respectively. There were no significant correla- 


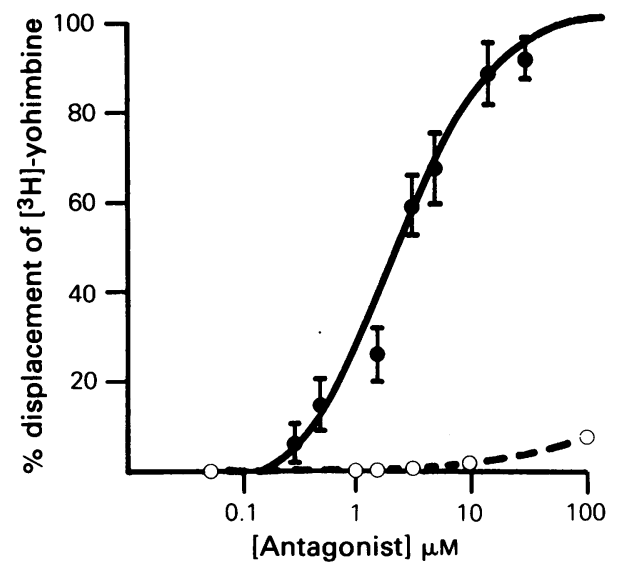

Figure 3 Verapamil and nisoldipine displacement of specifically bound $\left[{ }^{3} \mathrm{H}\right]$-yohimbine to whole platelets: verapamil $(\bullet)$, nisoldipine $(0)$.

tions with plasma levels of verapamil or its metabolite, norverapamil, and the changes in platelet aggregation $\left(\mathrm{C}_{50}\right.$ or $\left.\mathrm{E}_{\max }\right)$.

\section{Discussion}

The effects on platelet aggregation of verapamil and the dihydropyridine nifedipine have been examined in vitro in both animals and man (Johnsson, 1981; Kiyomoto et al., 1983). It has been shown that platelet aggregation induced by adenosine diphosphate is relatively resistant to inhibition by both verapamil and nifedipine. Our results confirm these findings in vitro. Similarly inhibition of platelet aggregation induced by adenosine diphosphate was observed, following the administration of both the first and multiple doses of both drugs in volunteers. This suggests that adenosine diphosphate triggers platelet aggregation through pathways which are not sensitive to blockade by calcium channel blockers. The role of calcium in adrenalineinduced platelet aggregation is under debate. Some authors using ${ }^{45} \mathrm{Ca}$ and chlortetracycline (Owen et al., 1980), the calcium fluorescent probes quin II (Erne et al. (1983) and aequorin (Johnson et al., 1983) have shown that adrenaline induced platelet aggregation is associated with calcium influx. Other authors have shown no change in platelet calcium during adrenaline activation in calcium free media within quin II (Bryden et al., 1984). The present study shows that caution must be exercised when using verapamil to examine whether or not pharmacological responses are calcium dependent. The inhibition of the adrenaline response by verapamil cannot be used to resolve this question since verapamil has been shown to have other properties in addition to its calcium channel blocking effects, with activity as an $\alpha$-adrenoceptor and muscarinic antagonist in rat myocardium (Karliner et al., 1982). Other authors using a different ligand have also found an interaction between verapamil and human platelet $\alpha_{2}$-adrenoceptors using $\left[{ }^{3} \mathrm{H}\right]-\mathrm{RX781094}$ to measure platelet $\alpha_{2}$-adrenoceptor number (Maisel et al., 1984). Verapamil has also been reported to act as an antagonist to platelet activating factor (PAF) induced calcium changes in platelets (Macintyre \& Shaw, 1982). Similarly caution must be used when interpreting the effects of nisoldipine in inhibiting the secondary phase of platelet aggregation. The related dihydropyridine nifedipine has been shown to be a thromboxane $\mathrm{A}_{2}$ antagonist (Addonizio et al., 1982). Platelets possess adrenoceptors of the $\alpha_{2}$ subtype (Motulsky et al., 1980) as detected by $\left[{ }^{3} \mathrm{H}\right]$-yohimbine binding.(Motulsky et al., 1980). The demonstration of the inhibition of specific $\left[{ }^{3} \mathrm{H}\right]$-yohimbine binding could be due to a direct interaction with $\alpha_{2}$-adrenoceptors or to steric hindrance due to the proximity of receptor operated calcium channels. The potency of verapamil as an $\alpha_{2}$-adrenoceptor blocker at platelet $\alpha_{2}$-adrenoceptors is similar to that observed with phenoxybenzamine (Brodde et al., 1982). The results of the clinical study in which oral dosing was continued for 4 days show that a significant inhibition of the aggregatory response to adrenaline, but not to adenosine diphosphate, may occur after both verapamil and nisoldipine in vivo in man. The peak plasma concentration measured during verapamil therapy was 10 -fold less than the concentration required to inhibit specific yohimbine binding in vitro by $50 \%$.

Table 1 Platelet aggregation responses to $1 \mu \mathrm{M}$ adenosine diphosphate ( $\Delta$ O.D mean \pm s.d.)

\begin{tabular}{llcl}
\hline & $\mathrm{n}$ & Acute & Chronic \\
\hline Placebo & 6 & $32 \pm 12$ & $33 \pm 13$ \\
Verapamil & 6 & $28 \pm 13$ & $26 \pm 14$ \\
Nisoldipine & 6 & $24 \pm 13$ & $23 \pm 13$ \\
\hline
\end{tabular}

Although there was some accumulation of the metabolite, norverapamil, during continued dosing this is less active at inhibiting platelet aggregation. The discrepancy between the effects during multiple dosing and the effects in vitro 

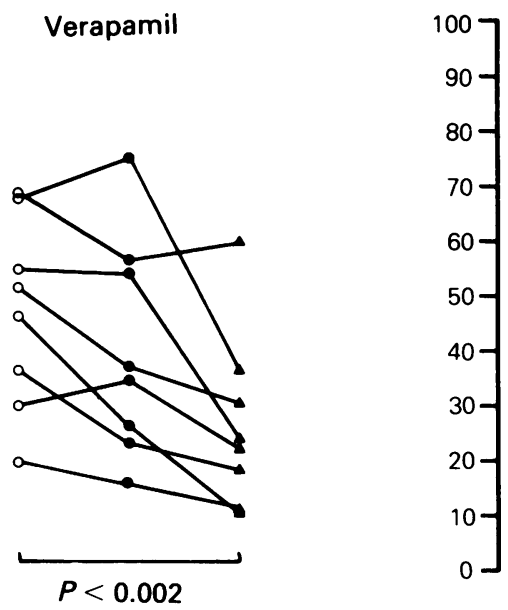

\section{Nisoldipine}
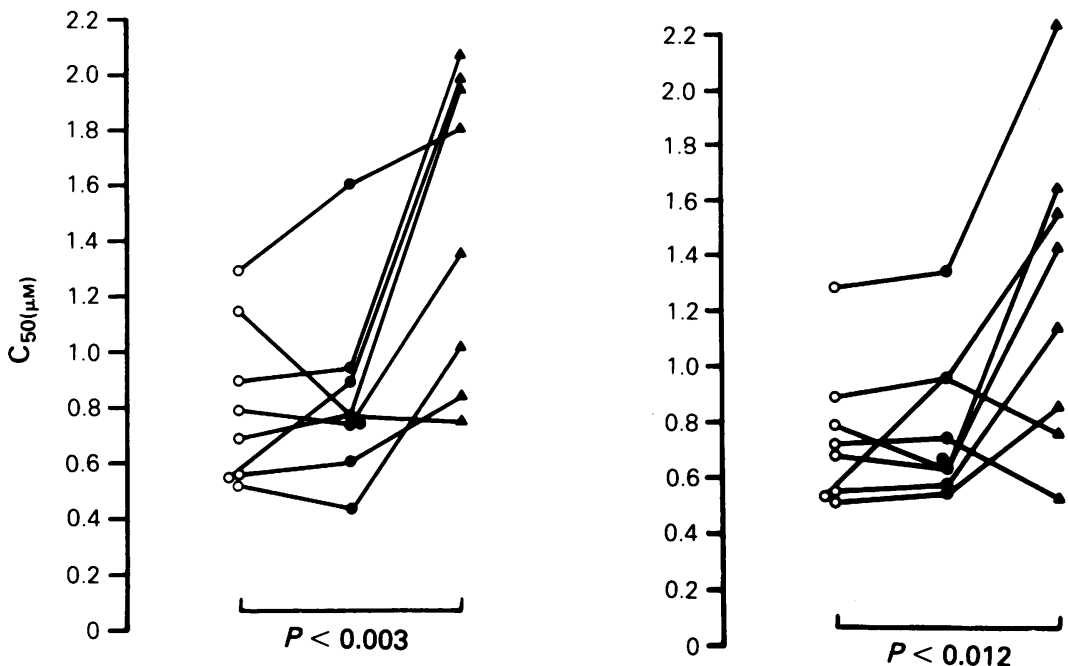

Figure 4 The effects of placebo $(0)$, the first dose $(\bullet)$ and 4 days treatment $(\Delta)$ with verapamil or nisoldipine on platelet aggregation in vitro induced by adrenaline expressed as the maximum rate of primary aggregation upper (Emax $\left.\Delta O D \mathrm{~min}^{-1}\right)$ and the concentration of adrenaline to achieve $50 \%$ of maximal aggregation $\mathrm{C}_{50}(\mu \mathrm{M})$; lower: $P$ values refer to significance levels obtained by comparing placebo with 4 day treatment values by paired $t$ test. No significant difference was found between the $E_{\max }$ values with nisoldipine treatment.

might also be due to accumulation of drug within the platelet. Alternatively, chronic ingestion of these agents may deplete intracellular calcium as has been reported with other antihypertensive agents (Erne et al., 1984).

In summary, the antiplatelet actions of both verapamil and nisoldipine may have implications for the primary prevention of atherosclerosis and the prevention of platelet mediated thrombosis in the treatment of hypertension and ischaemic heart disease. However, although adrenaline-induced platelet aggregation can be inhibited in vitro by both verapamil and nisoldipine, the evidence of this study indicates that the antiplatelet effects in vivo are mediated by a different mechanism.

CRJ is supported by a British Heart Foundation Fellowship and we thank Dr D. E. MacIntyre for helpful criticism. 


\section{References}

Addonizio, V. P., Wetsfan, L., Fisher, C. A., Feldman, P., Straus, J. F. \& Hanker, H. (1982). Mediation of cardiac ischaemia by thromboxane released by human platelets. Surgery, 92, 298-299.

Ardlie, N. G. (1982). Calcium ions, drug action and platelet function. Pharmac. Ther., 18, 249-270.

Born, G. V. R. (1962). Quantitative investigations into the aggregation of blood platelets. J. Physiol., 162, 67-70.

Brodde, O. E., Hardung, A., Ebel, H. \& Bock, K. D. (1982). GTP regulates binding of agonist to alpha adrenergic receptors in human platelets. Arch. int. Pharmacodyn., 258, 193-207.

Bryden, L. J., Drummond, A. H., Kirkpatrick, K. A., MacIntyre, D. E., Pollock, W. K. \& Shaw, A. M. (1984). Agonist-induced inositol phospholipid turnover and calcium influx in human platelet activation. Br. J. Pharmac., 81, P187.

Burns, E. R. \& Frishman, W. H. (1983). The antiplatelet effects of calcium channel blockers added to their anti anginal properties. Int. J. Cardiol., 4, 372.

Cheng, Y. \& Prusoff, W. H. (1973). Relationship between the inhibition constant $\left(K_{\mathrm{i}}\right)$ and the concentration of inhibitor which causes 50 per cent inhibition $\left(\mathrm{IC}_{50}\right)$ of an enzymatic reaction. Biochem. Pharmac., 22, 3099-3108.

Cole, S. C. J., Flanaghan, R. J., Johnston, A. \& Holt, D. W. (1981). Rapid HPLC method for the measurements of verapamil and norverapamil in blood, plasma or serum. J. Chromatogr., 218, 621629.

Erne, P., Buhler, F. R., Affulter, H. \& Burgisser, E. (1983). Excitatory and inhibitory modulation of intracellular free calcium in human platelets by hormones and drugs. Eur. J. Pharmac., 91, 331332.

Erne, P., Bolli, P., Burgisser, E. \& Buhler, F. R. (1984). Correlation of platelet calcium with blood pressure effect of antihypertensive therapy. New Engl. J. Med., 17, 1084-1088.

Han, P., Boutwright, C. \& Ardlie, N. G. (1983). Effect of the calcium entry blocking agent nifedipine in activation of human platelets and comparison with verapamil. Thromb. Haemostas., 50, 513-517.

Ingelfinger, F. J. A., Mostellor, F., Thibodean, L. A. \& Ware, J. H. (1983). Biostatistics in clinical medicine, p. 170. London: Macmillan.

Johnson, P. C., Clivedon, P., Sinith, M., Lall, P. \& Salzman, E. W. (1983). Measurements of cytoplasmic ionised calcium in platelets with the photoprotein aequorin comparison with Quin-2. Blood Suppl., 259a, 941.
Johnsson, H. (1981). Effects by nifedipine on platelet function in vitro and in vivo. Thromb. Res., 21, 523-528.

Karliner, J. S., Motulsky, H. J., Dunlop, J., Brown, J. H. \& Insel, P. A. (1982). Verapamil competitively inhibits alpha ${ }_{1}$ adrenergic and muscarinic but not beta adrenergic receptors in rat myocardium. $J$. cardiovasc. Pharmac., 4, 515-520.

Kiyomoto, A., Soouki, Y., Odawara, A. \& Morita, T. (1983). Inhibition of platelet aggregation by diltiazem, comparison with verapamil and nifedipine and inhibitory potency of diltiazem metabolites. Circ. Res., 52 (Suppl. 1), 115-119.

MacIntyre, D. E. \& Shaw, A. M. (1982). Selective inhibition of PAF-induced human platelet aggregation by verapamil and methoxyverapamil. $B r . J$. Pharmac., 77, 467.

Maisel, A. S., Motulsky, H. J. \& Insel, P. A. (1984). Hypotension after quinidine plus verapamil. Possible inhibition competition at alpha adrenergic receptors. New Engl. J. Med., 312, 167-171.

Mehta, J. \& Mehta, P. (1981). Platelet function in hypertension and effect of therapy. Am. J. Cardiol., 47, 331.

Motulsky, H. J., Shattil, S. J. \& Insel, P. A. (1980). Characterisation of alpha ${ }_{2}$ adrenergic receptors on human platelets using $\left[{ }^{3} \mathbf{H}\right]$ yohimbine. Biochem. Biophys. Res. Comm., 74, 1562-1570.

Owen, N. E., Feinberg, H. \& de Breton, G. C. (1980). Epinephrine induces $\mathrm{Ca}^{2+}$ uptake in human blood platelets. Am. J. Physiol., 239, H483-H488.

Rosenberg, L., Tickie, M. K. \& Triggle, D. J. (1979). The effects of $\mathrm{Ca}^{2+}$ antagonists on mechanical responses and $\mathrm{Ca}^{2+}$ movements in guinea pig ileal longitudinal smooth muscle. Can. J. Physiol. Pharmac., 57, 333-347.

Johnson, P. C., Cliveden, P., Smith, M., Lall, P. \& Salzman, E. W. (1983). Measurement of cytoplasmic ionised calcium in platelets with the photo protein aequorin comparison with Quin II. Blood, 62, 259(a).

Vanhoutte, P. M. (1982). Calcium entry blockers and vascular smooth muscle. Circulation, 65 (Suppl. I), 11-19.

Wang, T., Tsai, L. \& Schwartz, A. (1984). Effects of verapamil, idiltriazem, nisoldipine and felodipine on sacroplasmic reticulum. Eur. J. Pharmac., 100, 253-261.

(Received 5 March 1985, accepted 31 May 1985) 